\title{
Growing separation between teaching/ learning and research - anticipating the impacts from REF 2014
}

\author{
Ana Paula Cabral \\ University of Greenwich \\ Isabel Huet \\ University of Kingston
}

\begin{abstract}
Most quality assessment systems are based on an explicit separation of teaching/learning and research; however, in spite of their having enhanced both the organisation and quality improvement of each of these fields, they have also been contributing to a widening of the gap between the two and to the devaluation of teaching.
\end{abstract}

The present study, developed in the UK, intends to provide some insights into the perceptions of former panel members, managers and academics, as they anticipate the impacts from REF 2014. Increasing pressure to achieve high-quality research has been leading institutions to hire the most prestigious researchers. Were there to be equivalent effort to achieve parity in the quality of teaching, this situation might be less worrying, for teaching does not currently enjoy the same investment; rather, its very inferiority is considered to have an even more negative impact on the development of new practices, as well as on student learning and support.

Keywords: Research; Teaching; REF; Learning; Quality; Assessment.

\section{Introduction}

At present, Higher Education institutions (HEI.s) are constantly being challenged to rethink their roles, priorities and mission. Moreover, in a setting currently dominated by the notions of 'impact', 'funding' and 'marketisation', many distinct influences and forces have been contributing to significant changes in how both research and teaching are conceptualised, theorised about and practised.

Research into the roles of teaching/learning and of research in Higher Education has addressed these issues, using very distinct approaches and perspectives: the perspective of academics (Locke, 2014; Wells, 2013; Brown, 2011; Deem and Lucas, 2007), disciplines (Jenkins et al, 2007; Jenkins, 2005), departments (Durning and Jenkins, 2005), institutions (Watermeyer, 2014; Hattie and Marsh, 2004; Locke, 2004; Zamorski, 2002), national systems (Murphy and Sage, 2014; Harley, 2002) and the perspective of the students (Willets, 2013; Lindsay et al, 2002).

Overall, this debate has produced substantial but inconclusive literature about the connection between research and teaching quality, whilst the politics behind their assessment have caused pressures and created an imbalance between the values put on teaching/learning and on research. These quality assessment systems, although important 
tools of management and resource allocation, are, in fact, allowing the state to control universities and universities to control their academics.

We believe that, in the construction of knowledge and student learning, there is a lack of discussion about these impacts; considering the increasing demand for academics' involvement in high-quality research, it is a sensitive topic.

We argue that UK research assessment mechanisms, such as the Research Excellence Framework (REF), are creating a more competitive environment for research funding and leading to the danger of individual academics' prioritising research, with consequent decrement in teaching.

This argument is not new (Jenkins et al, 2003), but it is now a major concern among the academic community in the UK, especially in post-92 universities, where the pressure for research outputs is also growing. The culture of 'publish or perish' is here to stay and may send good teachers into the shadows or even compromise their careers if they do not accommodate institutional demands for research. This paper explores some of these challenges and sheds light on how teaching and research came to be divided, rather than coming together to improve the quality of students' learning.

On the basis of interviews conducted with the three key roles in the assessment process: panel members, research managers and researchers, we aim to contribute to a wider discussion about the growing teaching-research divide, perceived as one of the (un)intended impacts of the UK research assessment mechanisms.

\section{Research Quality Assessment in the UK}

In the last forty years, Higher Education in the UK has undergone profound change and experienced an impressive growth in the number both of universities and of students. The mechanisms for support, despite a trend of decline in public funding, have demanded a very significant increase in regulation and accountability.

Research funding is now based on a dual support system, whereby HEI.s can access funds through research councils or through periodic research assessment mechanisms that inform the distribution of government funding. Since its inception in 1986, the Research Assessment Exercise (RAE) has been greatly transformed and, since its last exercise in 2008, it has been replaced by the 2014 Research Excellence Framework (REF), with a stronger emphasis on bibliometrics and research impact, with the submission of case studies. The incorporation of 'impact' as a performance indicator within the REF was established at $20 \%$ of the total value available to each submission, with outputs (65\%) and environment (15\%) comprising the other generic criteria. Research is judged on its contribution to economic, social and cultural development and its impacts on public policy and improvement in the quality of life. The assessment mechanism also constitutes a source of relevant accountability data for public investment and the development of 'benchmarking information' and 'reputational yardsticks' (HEFCE, 2012). Additionally, with the introduction of tools (including journal impact factors) to measure the quality of research articles (four pieces of published work over six years), we find a clear call for evidence of the assessment of individual contribution and of hiring, promotion and funding decisions. 
This one-movement shift from assessment to excellence and emphasis on economic impact have raised questions about what is really being left behind and the possible effects of discarding research that does not translate into immediate measurable impact for public policy or industry in the UK. Furthermore, funding focuses on the internationally excellent or the world-leading, whilst institutions and managers deliberate over which academics to submit to the government's funding system. These procedures, with their focus on performance, are putting academics under huge pressure... and there is no mention of the link between research and teaching.

\section{REF challenges for teaching and learning}

As already stated, the assessments in the UK of the quality of teaching and of the quality of research are explicitly separated, with neither of the processes informing the other. In this context, research/teaching connections are questioned by funding regimes which are attempting to separate the two activities, even though the topic of their linkage is subject to debate at various levels and across disciplines and includes such variables as departmental cultures and institutional missions.

In the assessment process, the starting point is the unit of output (publication, patent...) produced by 'research-active' individuals within 'units of assessment' and usually aligned with academic departments (organised to deliver both teaching and research). However, research is often done in teams that cross those structural boundaries and, very often, interdisciplinary teams have to disaggregate to their parent disciplines and are then judged outside the context in which they perform research.

At the same time, the way teaching and research are organised within departments and institutions is also an important factor in determining the focus which is set on the organisation of disciplines for teaching and for research. These variations are shaped by the conceptions of the nature of knowledge, the different forms of pedagogy and curricula, and the impact of professional bodies and student interests on the content and practices of the disciplines. Moreover, questions have been raised about the mission and the way research is perceived and supported by institutions, especially when national policies and funding priorities are based on their separation (Jenkins, 2005; Hattie and Marsh, 2004).

One result is that "institutions have never been so divided as they are now between the worlds of teaching and research" (Macfarlane, 2011: 128) and this bifurcation has lowered the status of teaching and learning. At this level, in the UK, Young (2006) portrays an "out of balance" situation, referring to the differential value and rewards in relation to teaching and research based on lecturers' perceptions, and suggests that the impact of new developments to enhance teaching and learning are undermined by the persistent low status accorded to teaching. More recently, Locke (2014) presented the evolution of teaching and research in English universities between 1992 and 2007 and concluded that, in spite of variation in the mission and ethos of different universities (oriented either to research or to teaching) a university's success and prestige is still largely associated with research.

This divide is also evident in a report commissioned by the Higher Education Academy (2013), which has found out that more than two-thirds of university staff in the UK have never been recognised or rewarded for their teaching (just 28.4 per cent of academics have 
been rewarded for their commitment to teaching or student support) and concludes that promotion in the sector is too heavily based on research excellence.

At present, with the outcome of the last REF results, many institutions are even being relegated to teaching-only (or even training) status, while research is being concentrated on the Golden Triangle of London and Oxbridge (even to the detriment of northern Russell universities). At the same time, direct impact orientations have also revealed the clear danger that the distribution of research income concentrates even more on STEM subjects (science, technology, engineering and math), threatening such entire subject areas as social sciences, humanities and education, where impact or 'significance' is seen as a long-term, not-taken-for-granted achievement. In fact, many departments have also been closed or integrated in wider span approaches in order to 'meet the standards'.

Although there have been national moves towards recognition of teaching (most institutions and some universities have schemes to include teaching excellence as a criterion - among many others - for promotion and rewards), the actual impact of these initiatives is generally thought to be fairly limited and parity in esteem and financial reward a distant (or impossible) reality. Moreover, the attachment of funding to the assessment of research activities and not to the assessment of teaching (through teaching quality assessment) has been a crucial factor. This situation has made it difficult in practice for the staff dedicated to improving teaching to move their achievements from the private to the public domain, gain recognition for their work and acquire the credibility and status derived from research and publishing. At the same time, the problems of finding tangible and quantifiable evidence of excellence in the outcomes of teaching have simply served to consolidate the tendency to reward research activities.

Since the last RAE 2008 results, promotion procedures have been selecting the most competent members of staff and 'downgrading' the others to teaching associate or teaching fellow status, consigning them to teaching-only contracts or setting them aside for redundancy. Overall, this has understandably been leading members of staff to feel deterred from the academic teaching world and to question the real purpose of their role in the academy and in their daily work with students. More recently, on the basis of the depositions of senior academic managers from a range of social science research centres, Watermeyer (2014) highlighted the emergence of an impact agenda and its incorporation as a feature of the academic contract in UK universities, although stressing the potential of 'impact capture' as an obligation that enriches the perceptual horizons of research and the critical reflexivity of academics as knowledge workers. This trend was also stressed by Murphy and Sage (2014: 604), when suggesting that there is a very real sense amongst academics that the REF is adversely shaping the nature of research itself. In this context, reporting on the REF signals heightened pressures to publish and a developing culture of disregard for certain types of research in favour of short-term 'REF-able' work.

This concern has also been expressed by David Willetts (former minister for Universities and Science) who took a wide look at the UK Higher Education over the fifty years after the launch of Lord Robbins' seminal work (1963) about the nature and quality of higher education. According to Willetts (2013: 43), universities need a "cultural change back towards teaching" because the system has become "so lopsided away from teaching" (Willetts, 2013: 47) that universities need to rethink their role and priorities. Willetts argues that Robbins' vision was one in which research and teaching complemented each other, but 
that this idea has been lost. This argument has, in fact, supported the introduction of incomecontingent loans for students (a direct call for universities' attention to the need to take teaching more seriously).

In the same document, (Willetts, 2013: 42) takes into consideration the impact reported by students in the teaching and learning daily context. By comparing the situation of students between 1963 and 2012 (quoting data collected in a study developed with UK undergraduates, promoted by the Higher Education Policy Institute, HEPI, and commissioned by the consumer group Which? in 2013), the author argues that there had been a reduction in the amount of contact time students had with lecturers and in the quality of feedback provided about their work.

\section{Methodology}

The empirical study was organised and based on the collection of points of view, perceptions and experiences of the participants in the RAE system according to their profiles and roles. The sources of the data were semi-directed interviews $(n=6)$ conducted with two panel members from RAE 2008 (Cases A and B), two research managers (one from a worldleading research-led teaching approach institution and the other from a teaching-led /research-informed institution (Cases $\mathrm{C}$ and $\mathrm{D}$ ) and two senior (education) researchers (Cases $\mathrm{E}$ and F). Participants were invited to present their perceptions about the strengths, weaknesses, threats and opportunities of the research quality assessment system, bearing in mind their own perceptions of and experience with RAE 2008 and anticipating REF 2014.

The choice of participants accorded to their profiles, with the aim of including different types of roles in the assessment system and different types of institutions with different research drive approaches and research performances. The stated membership in panels, the direct discourse of representatives involved in institutional responses to assessment exercises and the publication of relevant and referenced work on the subject of the study fulfilled the established criteria for participants' selection.

The invitation was made by means of email and informal contacts, using contact people involved in the project's supervision and research networks. A whole set of validity and reliability procedures was developed, in order to ensure the trustworthiness of the data collected and its credibility (Lincoln and Guba, 1985), as well as the interpretation rigour (through the use of quotations to illustrate the concepts).

\section{Results}

The interviews provided a wide range of views and opinions to assess and draw conclusions from. A thematic analysis allowed the identification of the key ideas emerging from the data and codes were developed through the breakdown of data generated.

The analysis and data presentation structure emerged naturally from the content of the interviews, based on their common underlying themes which covered three general areas: addressing the teaching-research divide, unveiling the (un)intended consequences and closing the divide by calling for a wider conception of research. 


\section{Addressing the teaching-research divide}

An idea which emerged as a common theme was that the "focus of academics is set on research writing rather than teaching or service" (Case A). This concern is a clear reference to the perceived influence of the research assessment mechanisms in the development of effective teaching and to the pressures associated with the management and organisation of the academic work: research takes all the time and effort of the academics and, therefore, becomes their main goal (Murphy and Sage, 2014).

Respondents generally agreed that the UK's research assessment system reinforced: "a negative impact on the concern for teaching" (Case F), emphasising what is regarded as a "cultural prejudice concerning teaching because it doesn't give power and prestige" (Case $F$ ), where the "judgment of research is done in isolation and even from teaching" (Case E). It is relevant to see how these statements reflect a true hierarchy of esteem that rates research over teaching because, in practice, the teaching and research expectations of academic staff are often narrowly defined and considered as separate entities.

Overall, we believe that this growing separation is deeply rooted in the notion of reward: it is easier to base reward systems on research because its outputs can be clearly measured, while funding for teaching is generally formula-driven (i.e. numbers of students). In fact, "research success is generally the basis for promotion for academics, despite efforts to encourage and reward good teaching and an increased emphasis on student evaluation data in promotion systems" (Smith and Smith, 2012: 457). This situation is evident in the study conducted by Young (2006), where academics were consensual in feeling that the institution in which they worked didn't reward the effort put into teaching and time spent on developments to improve teaching. It is, somehow, implied that the system itself has impacted significantly on the performance of institutions and academics and on the way they face their financial and reputational success, associated with a shared alignment of interests and rewards.

\section{Unveiling the (un)intended consequences}

The dependency on funding and the pressure felt by researchers and institutions has been clearly highlighted by two of the respondents, who stated that "the name of the game is to publish and to do so quickly" (Case $\mathrm{C}$ ) and called for special attention and intervention to "prevent departments playing games to boost performance" (Case A). These concerns were already part of Lucas' work back in 2006, when arguing that, in the UK, academics were significantly engaged in playing an explicit 'research game', which, according to Deem (2010: 37), "goes well beyond academics' traditional concern to try to defeat their scientific competitors in their own field and is directly related to selective funding and research audit processes". Today, we consider that this publish or perish demand is clearly becoming a dilemma for academics: putting all the effort into publishing as many papers as possible in top-rated journals (regardless of the topic or approach ) or investing in developing relevant research to support their professional enrichment and the quality of their teaching.

This is explained by one of the respondents as being a clear "mitigation against some forms of research to publish quickly and preferably in top journals" (Case $\mathrm{C}$ ). These concerns are then presented as "threats to those who do not publish orthodox research or outlets" in a context where "researchers may be deterred from entering their work departments "(Case C) 
combined with a "restriction on the open pursuit of 'blue skies' research" (Case C). These comments evidence the areas affected by game playing, with implications in many of academics' research activities: academic capital (academic and scientific power, expertise and know-how), networks of academic contacts, their own area of discipline-based research expertise, work for academic journals, research grants, research outputs (including publications) and office-holding in learned societies (Deem, 2010).

We believe that this contributes, as one of the participants stressed, to a general "loss in terms of numbers of active researchers and of research capacity," caused by a policy that aims to concentrate funding on a small number of centres, "removing any expectation of significant research from many universities and individual academics" (McNay, 2007: 211). As a result, academics have tended to be designated as 'mainly teachers' or as 'researchactive', whilst postgraduate students and part-time teachers are taken on in order to free fulltime academics for research and young academics are offered "teaching-only" temporary posts (McLean and Barker, 2004). In Australia, such performance expectations of academic staff have led many to cope with these demands by using discretionary funds to buy themselves out of teaching activities in order to create the time for research and publication (Smith and Smith, 2012). In the UK, this idea of academics being designated as "mainly" teachers or researchers has been an intense area of discussion since the introduction of the first research assessment exercises when such concepts as 'research-active teaching' or 'research-led' teaching started being used in policy documents to determine the level of influence of research in teaching.

One of the participants considers that, when the quality assessment system is sharply focused on subjects and aims to link quality of provision to funding, improve quality and provide public information on quality to users (students and employers), some "unintended consequences" can lead to "damage to teaching and learning," especially when "the assessment system has no reference to the impact on students and no measurement of the key impact of the graduate/ postgraduate student learning" (Case F).

These remarks highlight the "lack of support to graduate and postgraduate students by their teachers" as a "result of the assessment needs and demands" (Case F) and suggest that students tend to experience some disadvantages from staff involvement in research particularly staff availability. In fact, it is not rare for academics to avoid engaging with students (some even consider it beneath them to teach at all, especially if those students are in the first year).

This negative impact was reported by Lindsay et al, (2002), distinguishing undergraduate and postgraduate teaching, with a more balanced score sheet in the latter. Moreover, studies conducted with British (Jenkins et al, 1998) and Australian (Neumann, 1994) undergraduates suggest that students from a range of disciplines perceive clear benefits from staff research, such as staff enthusiasm and the credibility of staff and of the institution. These benefits are also associated with the process of enriching teaching practice by including aspects of an academic's current research, or that of colleagues, in order to support student learning and one's teaching practice. Moreover, as stated by McLean and Barker (2004), students are, increasingly, becoming less able to gain from their teachers' research activity. Like Willetts (2013: 43), we believe we need to "revisit Robbins", call for "a cultural change back towards teaching" and realise that, above all, all academics involved in 
teaching are 'expert learners' helping 'novice learners' (Brew and Lucas, 2009; Brew, 1999: 297).

\section{Closing the divide: calling for a wider conception of research}

In the terms presented by one of the participants, there needs to be "established a wider conception of research" (Case F). At the same time, an idea to be worked out, according to another participant, is the notion that "research work can be done at low cost and closely related to daily occupations" (Case E), in an environment where "research is set in context and linked to purpose" (Case E) and where the "research agenda is informed by professional experience and for research findings to feed back in to practice"(Case E).

Calling out for a discussion about the fact that research assessments have been shaping the nature of research itself and that the creation of knowledge has been leaving no space for the specific contexts of the different areas of knowledge, one of the respondents stressed that we must acknowledge the dangers and damages of "using the same criteria for very different departments and different types of research" (Case C). Furthermore, one of the participants said that those who "work related to daily occupations may have an impression of low intensity with no rigour or originality" (Case E) referring to those developing research at the level of learning-teaching interfaces. This comment addresses a very relevant issue suggested by the feedback from panels: a call for more large-scale, quantitative, longitudinal studies. This situation can hardly be considered to be improving the quality of practice or informing teaching, the major objectives of much work in social sciences, as argued by McNay (2003), who also stresses the way academic autonomy is, therefore, conditioned by the degree of dependency on funding.

Another topic emerging from the participants' contributions is the negative impact of the exaggerated relevance attributed to specific types of publication outputs, as referred to in the "lack of value attributed to some sorts of publication that are relevant in the education research field (for example textbooks, e-learning materials...)" (Case F). In fact, despite general assessment guidelines, which allow the incorporation of publications relating to teaching and learning, evidence collected from teaching and through the wider networks of the subject centres is usually left aside or undervalued. Moreover, publishers are finding that academics are reluctant to write textbooks as those do not seem to be valued by assessment.

Additionally, participants mentioned a clear "preference for pure research and the dismission of applied and 'near market' research" (Case E), a situation explained by what is considered a "detachment from reality/ teaching caused by integration (of academics) in research centres" (Case E). Some points are also raised about how the research assessment systems can include data about teaching and students' learning through research and how the link between research and learning can be developed at a departmental level with the support of institutional leadership, planning and culture by "having assessment procedures and measures to value teaching" (Case F), "to value research on teaching and learning in the disciplines" (Case F) and "articulate the impact of research on learning" (Case E). Brew and Boud (1995: 268) articulated this specific relationship between research and learning by referring to learning as the "vital link between research and teaching", the "shared process in these two enterprises". 
As pointed out by one of the respondents, we believe the way forward should be based on the "recognition/ reward to the scholarship of teaching and pedagogy research" (Case F), the research context where academics from various disciplines do research about their own teaching and/or that of others, or focus on the way students learn - usually not considered 'proper' research and, therefore, not good for the purposes of research assessment (Macfarlane, 2011). Although controversial, this concept relates the two core activities through the concept of scholarship (Boyer, 1990) in a common effort to overcome some of the constraints limiting inter-disciplinary and applied work, and to reach a shared balance in terms of research autonomy.

\section{Concluding remarks}

This paper considers some aspects of the debate about the 'impact' that research assessment systems may have on teaching and student learning. These have been illustrated using data from the UK's experience in a setting where research and teaching quality are assessed separately.

The data helped us explore how, from the academics' point of view, such a separation can be damaging and have unintended consequences in the quality of both teaching and learning in higher education.

We have noted how the participants were very critical of this separation, highlighting the difficulties and threats it introduces. There was a clear sense that this 'impact-driven' system will make some academics more equal than others in terms of status and reward.

Where research-led teaching was formerly the key to high-quality undergraduate and graduate programmes, managers are now playing the game of maximising staff numbers and research outputs by declaring some staff as teaching-only. Research-active staff, by buying-out of their teaching, are entitled to funding, career enhancement, promotion and merit. A vicious circle, with teaching left to the research inactive, is the result.

We propose resisting the separation of teaching and research and propose its re-articulation, because there are conditions for a "positive link" (Elton, 2001). However, owing to policies made by government to assessment procedures and to reforms in the academic profession, the danger remains that students may be less able to gain from their teachers' research activity and academics may find themselves without the conditions, motivation or capacity to be excellent in both teaching and research. In order to preserve and enhance the motivation of staff involved in teaching and committed to learning, institutions should deal with the issue of parity of esteem for teaching.

Additionally, institutions need to close the divide and work with motivated academics who invest not only in research but also in the development of high-quality teaching. Moreover, effective research in education needs to be tested through teaching and university teaching needs to be driven by research. A significant proportion of the income of higher education institutions comes from teaching and this should be properly recognised and rewarded. After all, the quality of teaching and the reputation of the programmes are what attract students.

We argue for the enhancement of teaching, with its potential to connect with and inspire students, rather than having a single focus on the impact of research. Indeed, as a consequence of the Europe 2020 strategy, and of the Modernisation Agenda for Higher 
Education put forward in 2011, a set of recommendations for improving the quality of teaching and learning in European Higher Education institutions emerged in a June 2013 Report delivered to the European Commission. These recommendations put the emphasis on teaching, with the clear message that institutions should prioritise it: "Teaching is a core mission and therefore a core responsibility. Quality teaching is a sine qua non of a quality learning culture. That teaching mission should appear as a resounding priority throughout every institution involved in the delivery of higher education - a daily lived priority and not just worthy words in a mission statement" (European Commission 2013: 13). Are the recommendations proposed in this EC report an attempt to minimise the 'side-effect' of the pressure for research quality in European institutions? We are now curious to follow up the implications of these international guidelines in institutional/departmental practices and to monitor the success of such recommendations, as we envisage the 2020 horizon, on which a new REF - 2020 - is due to appear.

This research was developed as part of a post-doctoral grant (SFRH/BPD/69489/2010) from Fundação para a Ciência e a Tecnologia FCT-PORTUGAL, funded by POPH QREN (4.1) and supported by the European Social Fund and national funding (MEC, Portugal).

\section{Reference list}

Boyer, E. L. (1990) Scholarship Reconsidered: Priorities of the Professoriate. Princeton: Carnegie Foundation for the Advancement of Teaching.

Brew, A. (1999) 'Research and teaching: Changing relationship in a changing context.' Studies in Higher Education 24, 291-301.

Brew, A. and Boud, D. (1995) 'Teaching and research: establishing the vital link with learning.' Higher Education, 29(3), 261-273.

Brew, A. and Lucas, L. (2009) Academic Research and Researchers. Society for Research in Higher Education \& Open University Press.

Brown, C. (2011) 'Exploring the concepts of knowledge adoption and conceptual impact: implications for educational research submissions to the Research Excellence Framework (2014).' Education, Knowledge and Economy, 5(3), 137-154.

Deem, R. (2010) 'Herding the academic cats.' Perspectives: Policy and Practice in Higher Education, 14(2), 37-43.

Deem, R. and Lucas, L. (2007) 'Research and teaching cultures in two contrasting UK policy contexts: academic life in Education Departments in five English and Scottish universities.'

Higher Education, 54, 115-133. 
Durning, B. and Jenkins, A. (2005) 'Teaching-research relations in departments: the perspectives of built environment academics.' Studies in Higher Education, 30(4), 407-426.

Elton, L. (2001) 'Research and teaching: Conditions for a positive link.' Teaching in Higher Education 6(1), 43-56.

European Commission (2013) Report to the European Commission on improving the quality of teaching and learning in Europe's higher education institutions. Luxembourg: Publications of the European Union.

Harley, S. (2002) 'The impact of research selectivity on academic work and identity in UK universities.' Studies in Higher Education, 27(2), 187-205.

Hattie, J. and Marsh, H. (2004) 'One journey to unravel the relationship between research and teaching.' Research and teaching: Closing the divide? An International Colloquium, Winchester, March 18-19.

Higher Education Academy (2013) Measuring the Impact of the UK Professional Standards Framework for Teaching and Supporting Learning. SEDA commissioned by the Higher Education Academy.

Higher Education Funding Council for England (HEFCE) (2012) REF 2014: Assessment framework and guidance on submission (updated to include addendum published in January 2012).

Higher Education Policy Institute (HEPI) and "Which?" (2013) The Student Academic Experience Survey. Available at: http://www.hepi.ac.uk/wpcontent/uploads/2014/02/1.Higher_Educational_Report.pdf [Accessed: 02-03-2015]. Jenkins, A. (2005) Guide to the research evidence on teaching-research relations. York: Higher Education Academy.

Jenkins, A., Blackman, T., Lindsay R. and Paton- Saltzberg, R. (1998) 'Teaching and Research: Student Perspectives and Policy Implications.' Studies in Higher Education, 23(2), 127-141.

Jenkins, A., Healey M. and Zeller, R. (2007) Linking teaching and research in disciplines and departments. Higher Education Academy.

Lincoln, Y. and Guba, E. (1985) Naturalistic Inquiry. Newbury Park, CA: Sage Publications. Lindsay, R., Breen, R. and Jenkins. A. (2002) 'Academic research and teaching quality: the views of undergraduate and postgraduate students.' Studies in Higher Education, 27(3), 309-327.

Locke, W. (2014) 'Teaching and research in English Higher Education: the fragmentation, diversification and reorganisation of academic work, 1992-2007.' In: J. Shin, A. Arimoto, W.,Cummings, and U. Teichler, (eds.), Teaching and Research in Contemporary Higher Education, 319-334. London: Springer. 
Locke, W. (2004) 'Integrating Research and Teaching Strategies: Implications for Institutional Management and Leadership in the United Kingdom.' Higher Education Management and Policy, 16(1), 101-120.

Lucas, L. (2006) The Research Game in Academic Life. Maidenhead: SRHE/Open University Press.

Macfarlane, B. (2011) 'Prizes, pedagogic research and teaching professors: lowering the status of teaching and learning through bifurcation.' Teaching in Higher Education, 16(1), 127-130.

McLean, M. and Barker, H. (2004) 'Students making progress and the research-teaching nexus debate.' Teaching in Higher Education, 9(4), 407-419.

McNay, I. (2007) 'Research assessment; researcher autonomy.' In: Kayrooz, C, Akerlind, G. and Tight, M. Autonomy in Social Science Research, 183-216. Oxford: Elsevier.

McNay, I. (2003) 'Assessing the assessment: an analysis of the UK RAE 2001 and its outcomes.' Science and Public Policy, 30(1), 47-54.

Murphy, T. and Sage, D. (2014) 'Perceptions of the UK's Research Excellence Framework 2014: a media analysis.' Journal of Higher Education Policy and Management, 36(6), 603615.

Neumann, R. (1994) 'The teaching-research nexus: Applying a framework to university students' learning experiences.' European Journal of Education, 29(3), 323-338.

Smith, E. and Smith, A. (2012) 'Buying-out teaching for research: the views of academics and their managers.' Higher Education, 63, 455-472.

Watermeyer, R. (2014) 'Issues in the articulation of impact: the responses of UK academics to impact as a new measure of research assessment.' Studies in Higher Education, 39(2), 359-377.

Wells, P. (2013, January 23). 'The REF will strangle our vibrant academic community: It will alter morale, academic valuation of our work and the way in which we do it.' Impact of Social Sciences [Blog]. Available at:

http://blogs.Ise.ac.uk/impactofsocialsciences/2012/01/23/refwill-strangle-academia/

[Accessed: 02-03-2015].

Willetts, D. (2013) Robbins Revisited. Bigger and Better Higher Education. London: Social Market Foundation.

Young, P. (2006) 'Out of balance: lecturers' perceptions of differential status and rewards in relation to teaching and research.' Teaching in Higher Education, 11(2), 191-202.

Zamorski, B. (2002) 'Research-led Teaching and Learning in Higher Education, a case.' Teaching in Higher Education, 7(4), 411-427. 
Articles 